\title{
EXPERIMENTAL AND NATURAL ABRASION OF CONODONTS IN MARINE AND EOLIAN ENVIRONMENTS
}

BROADHEAD, Thomas W., Dept. of Geological Sciences, University of Tennessee, Knoxville, TN 37996-1410; DRIESE, Steven G., Dept. of Geological Sciences, University of Tennessee, Knoxville, TN 37996-1410

Small skeletal sediment particles, by virtue of their size, experience physical sedimentological conditions different from those affecting large (i.e., $>4 \mathrm{~mm}$ ) particles. In shallow, high-energy marine carbonate environments with an overall fine-grained $(<4 \mathrm{~mm})$ sediment composition, grain-to-grain impacts are probably of insufficient magnitude to overcome the cushioning effect of water and cause abrasive wear. Very large skeletal grains within such a setting will promote physical degradation, but biological activity (microboring, bioerosion) is more effective in modifying particle surfaces and diminishing grain size. Only in eolian environments are collisions between small grains effective in causing abrasion. Quartz sand, a particularly important abrasive agent in the destruction of large skeletal parts under even moderate energy regimes, also appears to be appreciably important for the degradation of small skeletons only under eolian conditions.

Conodonts are small $(0.2-2.0 \mathrm{~mm})$, phosphatic teeth, which may have belonged to an extinct (Cambrian-Triassic) group of jawless fish. They occur principally in marine and marginal marine sedimentary rocks; most specimens probably were deposited as discrete particles or as components of fecal masses. Because the extent and nature of degradation of a skeleton reflects its taphonomic history, evaluation of the susceptibility of conodonts to physical abrasion is important. Bioerosion, probably the principal cause of degradation of calcareous skeletons, was probably insignificant in alteration of conodonts. Their mineralogical composition made conodonts unlikely substrates for endoliths, and they were insufficiently abundant to serve as a recyclable source of phosphate for larger metazoans. Chemical breakdown of skeletal apatite would not have occurred, although atmospheric exposure may have promoted degradation of organic laminae, causing exfoliation.

Experimental studies of abrasion (elements of Palmatolepis sp., Polygnathus sp. - U. Devonian, Iowa) plus petrographic examination of conodont bearing marine, marginal marine, and eolian facies of the Morgan Formation (M. Pennsylvanian, Utah and Colorado) suggests that abrasion of conodonts is insignificant in aqueous environments, and likely to occur to a major degree only under eolian conditions. High-energy $(25.6 \mathrm{~cm} / \mathrm{sec})$ conditions were simulated in a tumbler containing quartz sand $(4 \phi-2 \phi)$, artificial sea water and moderate conodont abundances $(50$ specimens $/ \mathrm{kg})$. Abrasion produced under these artificially extreme conditions (e.g., continuous motion for up to $20 \mathrm{~km}$ travel distance) was at a scale detectable only with SEM. "Dry" tumbling experiments were ineffective, as noted by other authors simulating conditions for abrasion of mineral grains. Eolian conditions were simulated in a glass "wind tube" (see Kuenen, 1960, Journal of Geology) using a similar range of quartz sand sizes. Air velocity of approximately $100 \mathrm{~cm} / \mathrm{sec}$ produced subtle visually detectable abrasion following 5 hours of exposure/transport in $2 \phi$ quartz sand ( 1667 specimens $/ \mathrm{kg}$ ), but exhibited no visual evidence of abrasion under similar conditions with $3 \phi$ sand.

The Morgan Formation is a mixed carbonate/siliciclastic sequence that reflects repeated episodes of submergence and exposure of a carbonate shelf and laterally adjacent siliciclastic eolian "sand sea." It represents a virtually ideal ancient example for the interpretation of the effects of natural sedimentary processes because of its well-documented environmental heterogeneity and contains both abraded and unabraded conodonts. Conodonts sampled from high-energy subtidal carbonate facies of the Morgan are unabraded, irrespective of the presence of quartz sand; platform and delicate ramiform elements are all represented. Conodonts sampled from mixed siliciclastic/carbonate eolian facies are extremely abraded; only the most durable $\mathrm{Pa}$ elements of Adetognathus sp. and Idiognathodus sp. are preserved, although fine surface details and denticles are worn and anterior blades are missing. Laboratory simulations confirm the interpretation that marine processes are generally insufficient to physically abrade small phosphatic skeletal grains and that highly abraded Morgan conodonts experienced extremely long residence times in the eolian environment where they were transported, repeatedly buried, and exposed to bombardment and abrasion by quartz sand.

Supported by NSF EAR9004300 